\title{
Contingência e complexidade infinita: 0 problema da prova sortuda
}

\author{
Edgar Marques \\ edgarm@terra.com.br \\ Universidade Estadual do Rio de Janeiro, Rio de Janeiro, Brasil/ Cnpq
}

resumo Apresento e desenvolvo neste artigo o problema da prova sortuda, analisando duas soluções para ele presentes na literatura. A primeira delas consistira em alegar que mostrar que o predicado está contido no sujeito não basta como demonstração da verdade de uma proposição, sendo preciso que se prove ainda que a noção relativa ao sujeito é logicamente consistente. A segunda repousaria em uma hierarquização modal, por assim dizer, dos predicados integrantes de uma noção individual. Após exibir as razões que me levam a rejeitar essas duas soluções, apresento os traços fundamentais de uma interpretação que me parece resolver o problema de maneira satisfatória. Minha posição envolve conceder ao Princípio da Razão Suficiente um papel central na compreensão do que significa, para Leibniz, provar que um determinado predicado está contido na noção relativa a um certo indivíduo.

palavras-chave Leibniz; contingência; prova finita; problema da prova sortuda; análise; indivíduo

A adoção, por parte de Leibniz, da concepção segundo a qual em toda proposição verdadeira a noção do predicado está contida na noção do sujeito $^{1}$ torna extremamente dificil que se sustente de maneira coerente, no interior do sistema leibniziano, o caráter contingente de ao menos algumas das proposições verdadeiras, uma vez que se a verdade envolve a continência da noção do predicado na noção do sujeito e se proposições contingentes são aquelas cuja negação não é contraditória, então a filosofia de Leibniz não parece reservar nenhum espaço para proposições que sejam tanto verdadeiras quanto contingentes. O problema é que a 
aceitação da tese de que a verdade de uma proposição consiste na inclusão da noção do predicado na noção do sujeito parece implicar que a negação de toda proposição verdadeira deva ser contraditória, o que faria com que todas as proposições verdadeiras fossem necessárias, e não contingentes. Assim, se, por exemplo, a proposição "César atravessou o Rubicão" é verdadeira por estar a noção relativa à ação de travessia do Rubicão incluída na noção completa de César, então a proposição "César não atravessou o Rubicão" deveria ser contraditória, dado que a noção de César já inclui em si a noção da realização da travessia do Rubicão. Sendo contraditória a sua negação, a proposição "César atravessou o Rubicão" seria, dessa maneira, necessária.

Leibniz tem plena consciência de que a noção de verdade por ele assumida torna problemática a afirmação de que algumas proposições verdadeiras são contingentes. Com o propósito de, por assim dizer, resgatar a contingência, ele desenvolve ao longo de sua obra filosófica diferentes conceitos e estratégias argumentativas. Uma das mais engenhosas soluções consiste na consideração de que podemos diferenciar proposições contingentes das necessárias apelando para o tipo de demonstração associado às proposições. No caso das proposições necessárias, a demonstração da inclusão da noção do predicado na noção do sujeito seria realizada em um conjunto finito de etapas, enquanto no caso das proposições contingentes essa demonstração envolveria infinitos passos, não chegando, assim, nunca a termo. Dito de outra forma: uma proposição seria contingente quando a redução dela a um enunciado de identidade envolvesse um procedimento demonstrativo que se prolongasse ao infinito ${ }^{2}$.

A elucidação plena do sentido e alcance dessa solução para o problema da contingência exige que se esclareça por que a demonstração de algumas proposições pode ser feita em passos finitos enquanto a demonstração de outras envolveria um conjunto infinito de passos. Louis Couturat foi o primeiro intérprete da filosofia de Leibniz a fornecer uma resposta precisa a essa questão. Segundo Couturat (COUTURAT, 1901, cap.VI), uma análise acaba por se prolongar ao infinito quando se tenta reduzir a um enunciado de identidade uma proposição cujo termo sujeito denota um indivíduo, pois toda noção relativa a um ente singular abarca infinitos elementos. O ponto principal é o de que a noção completa de todo indivíduo tem de englobar infinitas determinações, pois todo indivíduo possui 
um número infinito de propriedades e se encontra imerso em infinitas relações. Uma vez que a referência a qualquer sujeito individual implica sempre a consideração de infinitos elementos e de infinitas condições, é simplesmente impossível - não apenas factualmente impossível, mas impossível de direito - que se demonstre que em uma proposição acerca de um indivíduo singular - César, por exemplo - a noção do predicado está incluída na noção do sujeito, pois a demonstração dessa inclusão somente poderia se dar caso esse infinito pudesse ser percorrido. A infinita complexidade das noções referentes aos indivíduos estaria, assim, na base da contingência, constituindo, empregando aqui uma expressão cara a Leibniz, a sua raiz.

A ideia central na interpretação de Couturat é, então, a de que a prova de uma proposição - isto é, a redução dela a um enunciado de identidade - cujo sujeito seja um indivíduo singular implica infinitos passos, pois as noções completas relativas a indivíduos são infinitamente complexas por serem infinitamente complexos os indivíduos aos quais elas se referem. Para provar que um determinado predicado está incluído na noção completa de um indivíduo seria necessário, assim, percorrer esse infinito de determinações, o que obviamente não pode ser feito. Dessa maneira, apesar de o predicado estar incluído no sujeito das proposições verdadeiras acerca de indivíduos, não pode existir uma prova a priori dessa inclusão. Como essa inclusão não pode ser provada, a negação dessas proposições não gera contradição, sendo tais proposições, portanto, contingentes ${ }^{3}$.

Em seu livro sobre Leibniz (ADAMS, 1994), o sempre sagaz Robert Adams aponta uma dificuldade para essa solução do problema da contingência. Ele chama atenção para o fato de que ainda que o conceito completo de um indivíduo contenha infinitas propriedades, a análise desse conceito começará sempre com alguma dessas propriedades, progredindo paulatinamente de propriedade em propriedade, e assim ao infinito. Se quisermos provar, por exemplo, a proposição "César atravessou o Rubicão", a análise da noção de César começará com a explicitação de alguma das infinitas propriedades que César possui, abarcando a cada vez uma nova propriedade. Ainda que sejam infinitas essas propriedades, nada parece impedir que, em um conjunto finito de passos, tenhamos a sorte de que precisamente a propriedade relacional relativa à travessia do Rubicão seja determinada como pertencente à noção de César. Isto é, mesmo 
levando em consideração de que a noção completa de César abrange infinitas propriedades, a prova de que uma determinada propriedade pertence a essa noção parece não precisar se estender ao infinito, pois tudo o que precisamos é mostrar que essa noção inclui essa propriedade, e isso, ao menos aparentemente, deve poder se efetivar a qualquer momento da análise. Se estivermos em um daqueles dias de rara sorte em que tudo dá certo - li em algum lugar que existem tais dias -, nossa análise da noção de César pode até mesmo ter como primeiro resultado a exibição da inerência em César da travessia do Rubicão. Quer dizer, ainda que a análise completa da noção de César nunca possa ser levada a termo dada a infinitude dessa noção, isso não parece implicar que a prova de que um determinado predicado integre essa noção não possa ser realizada, pois, à primeira vista, basta que em algum dos passos dessa análise infinita o predicado em questão seja precisamente o predicado cujo pertencimento ao sujeito se deseja provar. Para preservar a solução, em Leibniz, do problema da contingência por meio do recurso à contraposição entre provas finitas e provas infinitas, seria preciso, então, apresentar alguma razão que permitisse que afastássemos a possibilidade de que uma dessas primeiras propriedades resultante da análise, por exemplo, da noção de César fosse, em um raro golpe de sorte, precisamente a de ter atravessado o Rubicão. ${ }^{4}$ Nos casos em que fôssemos bafejados pela sorte, conseguiríamos, apesar da infinitude das noções completas das substâncias individuais, provar que um determinado indivíduo possui um certo predicado, o que faria cair por terra nosso critério distintivo entre proposições necessárias e proposições contingentes. Dessa maneira, o apelo simples e não qualificado à complexidade infinita das noções completas relativas a indivíduos somente poderá fundamentar a contingência das proposições acerca de indivíduos caso se apresente algum argumento contra a possibilidade de uma prova sortuda [lucky proof].'

Hawthorne e Cover tentam, em um artigo publicado em 2000 (HAWTHORNE \& COVER, 2000, pp. 151-165) encontrar uma solução para o problema da prova sortuda. Eles apresentam duas soluções possíveis, argumentando contra a primeira delas e em favor da segunda. Essas mesmas soluções são retomadas por Rodriguez-Pereira e Lodge em um artigo de 2011 (RODRIGUEZ-PEREIRA, \& LODGE, 2011, pp. 222-236), mas, curiosamente, com o objetivo contrário, qual seja, o de 
defender a primeira solução e atacar a segunda. Considero que as duas duplas de intérpretes estão certas em suas críticas e equivocadas em suas defesas. Tentarei, no que segue, após apresentar primeiramente essas duas soluções e as razões em função das quais julgo serem ambas insatisfatórias, expor as ideias centrais do que julgo ser uma solução - ou, a bem da verdade, uma dissolução - aceitável para esse problema.

\section{$* * *$}

Com o propósito de formular uma primeira solução concebível para o problema da prova sortuda, Hawthorne e Cover recordam que, para Leibniz, provas a priori de existência não podem se restringir à demonstração da inclusão do predicado no sujeito, devendo, ao contrário, envolver também uma prova de que a noção expressa pelo termo sujeito consiste em um conceito coerente, isto é, consiste em um conceito que não possui nenhuma contradição interna. Essa condição adicional a ser satisfeita por esse gênero de prova é tornada explícita por Leibniz em sua crítica ao argumento ontológico cartesiano.

Em um texto escrito provavelmente em 1679, Leibniz tece as seguintes considerações acerca do argumento de Descartes:

Descartes argumenta da seguinte maneira: qualquer coisa que possa ser demonstrada a partir da definição de algo pode ser atribuída a esse algo. Assim, da definição de Deus (que é o ente sumamente perfeito, ou, como o diziam alguns escolásticos, o ente do qual não se pode pensar em nada maior) segue-se sua existência (dado que a existência é uma perfeição e qualquer coisa que possua existência será maior do que seria sem ela); logo, a existência pode ser predicada de Deus, Deus existe. (....) Mas, para que essa prova seja rigorosa, essa possibilidade tem de ser primeiramente provada. É claro que não podemos formular uma demonstração rigorosa de nenhuma noção a não ser que saibamos que ela é possivel, pois partindo de noções impossíveis ou que envolvam contradições coisas contraditórias podem ser demonstradas. Essa é uma razão a priori de a possibilidade ser um requisito das definições reais. (LEIBNIZ, 1978, 7, p. 261-262) ${ }^{5}$ 
Leibniz considera, então, insatisfatória a prova cartesiana pelo fato de ela não conter a prova da possibilidade de Deus. Segundo a filosofia leibniziana, a possibilidade de um ente é provada quando se prova que a noção relativa a esse ente não apresenta nenhuma inconsistência interna, isto é, que ela não contém determinações que se contradigam mutuamente. Dessa maneira, sua complementação ao argumento ontológico de matriz cartesiana consiste precisamente na prova de que o conceito de Deus não envolve contradição ${ }^{6}$.

Aplicando essa exigência leibniziana de prova da possibilidade do sujeito em questão a todas as proposições nas quais façamos afirmações de qualquer natureza acerca de indivíduos finitos singulares, teremos como resultado não haver nenhuma prova a priori acerca do pertencimento de nenhuma propriedade relacional ou não-relacional a nenhum sujeito finito singular, dado que, em função de serem infinitas as modificações de qualquer indivíduo não há, por princípio, como nos assegurarmos de que a noção do sujeito não contenha determinações mutuamente contraditórias. Não é possível que se prove a priori a consistência da noção relativa a nenhum indivíduo finito singular, pois não se pode expor todas as suas propriedades, uma vez que se trata de um conjunto infinito. Quer dizer, em nenhum momento da análise pode ser excluída a possibilidade de que em um dos passos seguintes venha a ser exposta uma propriedade cuja posse seja contraditória com a posse de alguma propriedade já exibida. Não poder provar a consistência de uma noção relativa a um sujeito singular equivale a não poder provar a possibilidade de um indivíduo finito, isto é, equivale a não poder produzir nenhuma prova a priori acerca dele.

Dessa maneira, de acordo com essa concepção, mesmo que tivéssemos uma incomum sorte em nossa análise de uma proposição como "César atravessou o Rubicão" e em dos primeiros passos extraíssemos da noção de César exatamente o predicado relativo à ação da travessia do Rubicão, ainda assim não teríamos provado a priori a verdade dessa proposição, pois para isso teríamos de provar a priori a possibilidade de César, isto é, teríamos de provar que a noção de César não contém predicados que sejam mutuamente contraditórios, o que não pode ser feito, uma vez que, dada a infinitude dos predicados que integram a noção de César, ela não pode nunca ser completamente decomposta. Poderia acontecer, por exemplo, de o predicado relativo à não-travessia do Rubicão estar 
igualmente contido na noção de César, o que faria com que ela fosse uma noção inconsistente, que não corresponderia a nenhum ente possível.

Assim, a mera demonstração de que, por exemplo, o predicado "atravessou o Rubicão" está contido na noção de César não seria suficiente para provar a verdade da proposição "César atravessou o Rubicão", uma vez que isso não garantiria por si só que o predicado relativo à não-travessia do Rubicão não integre também essa noção. Evidentemente que sabemos a posteriori que César existiu e que, portanto, a noção completa relativa a ele é consistente, mas trata-se aqui da possibilidade de uma prova a priori acerca de uma proposição contingente, não sendo válido o apelo àquilo que se sabe a posteriori.

Em suma, caso seja aceitável a introdução do requisito da prova da consistência da noção completa das substâncias individuais para que se possa demonstrar a priori uma proposição qualquer acerca de um sujeito individual o problema colocado pela prova sortuda é dissolvido, pois mostrar que o predicado está contido no sujeito não basta como demonstração da verdade da proposição, sendo preciso que se prove ainda - o que não é possível no caso das noções constituídas por infinitas determinações - que a noção relativa ao sujeito é logicamente consistente. Com isso, a diferença entre as proposições necessárias e as contingentes com base no tipo de prova associada a elas - as proposições necessárias se deixam provar em um número finito de passos, enquanto a prova das contingentes exigiria que percorrêssemos infinitas etapas - pode ser mantida independentemente da possibilidade de haver provas sortudas e dias em que tudo dá certo.

Entretanto, apesar de sua inegável plausibilidade inicial, não me parece ser possível sustentar essa solução para o problema da prova sortuda pelo simples fato de ela tornar contingentes todas as proposições acerca de indivíduos ${ }^{7}$, o que creio ser incompatível com a metafísica de Leibniz. Senão vejamos. Se essa estratégia for correta, então todas as predicações acerca de indivíduos - exceção feita à afirmação de que Deus existe serão contingentes, pois não há como, em um número finito de passos, provar a consistência de uma noção que envolve infinitas determinações. Dessa maneira, todas as seguintes proposições acerca, por exemplo, de César seriam contingentes, uma vez que não podemos provar a priori a consistência da noção de César. 
(1) "César atravessou o Rubicão"

(2) "César é um ser humano"

(3) "César é César"

Enquanto (1) seria, a meu ver, para Leibniz, o caso paradigmático de uma proposição contingente, as proposições (2) e (3) parecem, apesar de o termo sujeito nelas presente ser um termo singular relativo a uma substância individual finita, dever ser compreendidas como proposições necessárias, isto é, como proposições cuja negação seria contraditória. Lançando mão da imagem dos mundos possíveis, tantas vezes explorada por Leibniz em seus textos, poderíamos dizer que, ao menos prima facie, não haveria mundos possíveis nos quais as proposições (2) ou (3) fossem falsas. Examinemos, contudo, com um pouco mais de atenção cada uma dessas proposições.

A proposição (1) expressa a atribuição a César de uma certa ação temporal, a saber, a ação de travessia do Rubicão. Considerar que essa proposição é contingente significa, em um primeiro momento, simplesmente considerar que sua negação não é contraditória, isto é, que não incorre em absurdo ou em contradição quem a negue. Dizer que a negação de (1) não é contraditória é dizer que ainda que César tenha de fato atravessado o Rubicão, ele poderia ter agido de outro modo. Trata-se, então, de um ente concebível - e Deus, em seu entendimento infinito, efetivamente o concebe - o César que não atravessa o Rubicão e opta por permanecer na Gália em vez de desafiar o senado romano.

Já a proposição (2) parece possuir uma natureza completamente distinta daquela da (1). Enquanto (1) envolve a atribuição a César de uma ação localizada em um certo momento do tempo e em uma certa região do espaço, não fazendo, portanto, sentido falar da atribuição a César desse predicado independentemente desse contexto específico no qual essa ação se apresenta como uma possibilidade ${ }^{8}$, o atributo de ser um ser humano consiste em algo que está presente em César em todos os momentos de sua existência independentemente de onde ele esteja. Não há, e não pode haver, situações nas quais César exista e não seja um ser humano. Quer dizer, não se pode conceber de forma coerente e consistente um estado de coisas relativo a César - e não a um outro ente - no qual ele seja algo outro - um tomate, por exemplo - que um ser humano. Como todos os entes, César possui, para Leibniz, uma essência específica, 
que expressa o tipo de ente que ele é, no caso, um ser humano. Como a posse do predicado de ser um ser humano consiste em algo inextirpável de César, a humanidade está presente nele em todos os momentos, não havendo descontinuidades temporais no seu inerir em César. Sendo assim, é contraditória a negação da humanidade a César, pois ele, na medida em que é o ente que é, não pode não ser um ser humano.

O ponto que eu gostaria de defender aqui é, então, o de que proposições como "César é um ser humano" são, para Leibniz, necessárias - e não contingentes -, pois elas consistem na atribuição a um indivíduo de uma característica integrante da sua essência específica, sendo, em função disso, contraditória sua negação. Já os predicados cuja atribuição envolve a totalidade da noção completa da substância individual - e não apenas uma “parte” dela -0 serão contingentes. É exatamente essa distinção entre esses dois tipos de predicados que se encontra em um texto de Leibniz escrito provavelmente entre os anos de 1686 e 1687:

Nessa noção completa do Pedro possível, a qual concedo que se oferece à observação de Deus, não apenas se encontram contidos os essenciais ou necessários, os quais fluem evidentemente das noções incompletas ou específicas, e isso de tal maneira que se demonstram a partir dos termos, implicando seu contrário contradição, senão que também estão contidos os existenciais ou, por assim dizer, contingentes, uma vez que é da natureza da substância individual, a fim de que sua noção seja perfeita e completa, conter todas as circunstâncias individuais e contingentes por mínimas que sejam. (LEIBNIZ, 1978,VI, 4, p. 1600)9

Se essas minhas observações acerca da compreensão leibniziana do estatuto de proposições semelhantes a "César é um ser humano" forem corretas, então a solução para o problema da prova sortuda através do recurso à ideia de que a demonstração de uma proposição acerca de um indivíduo pressupõe a prova da possibilidade do indivíduo em questão não poderá ser aceita, pois, de acordo com essa solução, todas as proposições acerca de indivíduos são contingentes.

Mesmo que minhas observações acerca de proposições do tipo (2) fossem falsas, isso não significaria, contudo, que teríamos de aceitar essa solução, pois independentemente da tese que atribuamos a Leibniz sobre predicados essenciais e acidentais, parece indiscutível que uma proposição 
como "César é César", por ser um enunciado de identidade, consista, a seus olhos, em uma proposição necessária, ainda que seja - e como poderia ser diferente? - uma proposição acerca de César. Senão vejamos. No parágrafo 60 das Investigações Gerais, Leibniz caracteriza como sendo necessárias todas as proposições que se deixam reduzir a proposições idênticas ou aquelas cujas opostas podem ser reduzidas a proposições contraditórias ${ }^{10}$. Isso significa que todas as proposições idênticas são necessárias, independentemente da natureza dos termos que as compõem. Assim, independentemente do fato de ser acerca de César, a proposição "César é César" é necessariamente verdadeira, não dependendo sua verdade da prova da consistência e coerência da noção mesma de César. A verdade dessa proposição não envolve, dessa maneira, o recurso ao infinito, apesar de ser acerca de um indivíduo, contrariando o que afirma a solução para o problema da prova sortuda, que apela para a ideia de que a prova de toda proposição acerca de um indivíduo pressupõe a - irrealizável no caso de substâncias criadas - prova da consistência da noção relativa a esse indivíduo.

Hawthorne \& Cover apresentam - e defendem - em seu artigo uma segunda solução para o problema da prova sortuda. Trata-se de uma solução extremamente engenhosa e interessante, mas que, por razões que apresento mais abaixo, também não pode ser aceita. Essa solução envolve, em primeiro lugar, uma distinção entre os predicados que costumeiramente atribuímos às substâncias individuais nas predicações que fazemos diuturnamente acerca delas - Hawthorne \& Cover os chamam de macro-predicados - e as infinitas pequenas inclinações instantâneas básicas [minute basic inclinations] que constituiriam essas substâncias em seu estado inicial. De acordo com eles, a noção completa de uma substância individual compreenderia esse conjunto infinito de pequenas inclinações juntamente com sua lei de desenvolvimento, isto é, a lei própria a cada substância e que a inclina aos estados que ela assumirá subsequentemente na ordem temporal. Dessa maneira, os macro-predicados não estariam contidos nas noções completas das respectivas substâncias individuais, contendo essas, ao contrário, unicamente predicados mais básicos dos quais aqueles predicados, em função da lei da série de cada substância, seguir-se-iam.

Em termos exegéticos, poderíamos argumentar em favor da atribuição a Leibniz dessa contraposição entre dois conjuntos de predicados - de um 
lado os mais básicos e de outro os derivados -, assinalando que Leibniz parece lançar mão dela nas anotações feitas por volta de junho de 1686, para uma carta que ele enviará a Arnauld em julho daquele mesmo ano. Em um trecho dessas anotações ele faz a seguinte observação:

Pois cada predicado de Adão ou depende de outros predicados do mesmo Adão ou não depende. Colocando de lado aqueles que dependem de outros, basta tomar em conjunto todos os predicados primitivos para formar a noção completa de Adão suficiente completa para que se deduza tudo o que lhe ocorrerá na medida em que se pode explicar (LEIBNIZ, 1993, p. 110). ${ }^{11}$

A noção completa de Adão incluiria, assim, os predicados primitivos de Adão, e não os que deles se derivam.

Concedida essa distinção, a segunda solução interpretativa para o problema da prova sortuda proposta por Hawthorne \& Cover envolverá apenas dois passos adicionais. O primeiro deles consiste em considerar que, lançando mão unicamente de um instrumental lógico, os predicados derivados - os macro-predicados - não se deixam deduzir a partir de inclinações instantâneas básicas - os micro-predicados - especificadas. Isso ocorre porque nenhum conjunto finito de inclinações instantâneas é, de acordo com Leibniz, suficiente para determinar nenhum estado posterior de uma substância individual. É a soma de todas as infinitas pequenas modificações de um sujeito - as pequenas percepções e apetites - em um dado instante que determinam o estado em que ele se encontrará no momento seguinte. Qualquer conjunto finito de percepções e apetites, não importando quão extenso e abrangente ele o seja, apenas inclinará o sujeito em uma ou outra direção. Não haveria como, portanto, listar um conjunto de micro-predicados de um sujeito e dele extrair a priori a verdade da atribuição a esse mesmo sujeito de um certo macro-predicado.

Considerando, em segundo lugar, que, de acordo com essa interpretação, unicamente micro-predicados estão contidos na noção completa de uma substância individual, então todas as predicações acerca de indivíduos serão contingentes, pois, independentemente da nossa sorte, nunca encontraremos um macro-predicado ao analisarmos uma noção completa de uma substância individual simplesmente porque uma tal noção não contém predicados desse tipo. Além disso, conforme o que se disse 
no parágrafo anterior, não importa quantos micro-predicados extraiamos da noção completa de um indivíduo, nós nunca estaremos em condição de provar a priori que da posse desses micro-predicados se deixe deduzir a posse de um determinado macro-predicado, não sendo, possível, então demonstrar que a noção completa relativa a um indivíduo inclua ou implique a posse por esse indivíduo de uma macro-propriedade. Dessa maneira, a impossibilidade da obtenção de uma prova a priori de proposições que envolvam a atribuição a indivíduos de macro-propriedades não estarão sujeitas às dificuldades levantadas pelo problema da prova sortuda. Simplesmente não há provas sortudas possíveis para proposições desse tipo.

São razões de diferentes ordens que me levam a considerar insatisfatória a solução proposta por Hawthorne \& Cover. Em primeiro lugar, em termos exegéticos, não é de maneira nenhuma claro que os predicados primitivos ou básicos aos quais Leibniz faz referência possam ser identificados, tal como Hawthorne \& Cover o fazem, a micro-predicados. Considero, ao contrário, que uma tal assimilação é fundamentalmente equivocada, pois, os predicados básicos, ainda que constituam um conjunto infinito, devem poder ser discriminados individualmente, enquanto as pequenas percepções e os pequenos apetites, em função de sua natureza infinitesimal, não se deixam individualizar, pois eles consistem, em última instância, em meros produtos de percepções e apetites ainda menores e ainda mais instantâneos, e assim ao infinito. Dessa forma, por serem estados instantâneos dos sujeitos, e que, como tal, se subdividem ao infinito tanto no que diz respeito à sua duração quanto no que tange ao seu conteúdo intencional, as pequenas percepções e os pequenos apetites não parecem poder ser, no sentido de Leibniz, predicados primitivos.

Uma outra questão - e aqui creio que resida a dificuldade principal com a qual essa solução se depara - é que não creio que, em função de sua natureza, esses estados infinitesimais instantâneos sejam conceitualizáveis ${ }^{12}$, pois tais estados, por definição, não se distendem no tempo - eles são instantâneos - nem podem se reapresentar ao sujeito, o que impossibilita que seu conteúdo intencional seja conceitual, pois a possibilidade de reaplicação - e, portanto, de reidentificação - é essencial às representações conceituais. Além disso, o conteúdo das pequenas percepções e dos pequenos apetites não possui nenhum tipo de autonomia e estabilidade 
constitutiva em relação ao conteúdo das ainda menores percepções e dos ainda menores apetites que os compõem, não possuindo, assim, uma unidade estrutural minimamente estável que possibilite que esse conteúdo instancie conceitos, dado que uma instância de um conceito, para poder ser discriminada e identificada, tem de constituir de alguma maneira um todo, não podendo se resumir a um mero amálgama de suas partes.

Da tese de que o conteúdo das pequenas percepções e dos pequenos apetites não pode, por uma questão de princípio, ser de natureza conceitual, segue-se a tese de que os predicados básicos que integram a noção completa de uma substância individual não podem ser pequenas percepções e pequenos apetites, uma vez que a inerência desses predicados básicos na substância, exatamente por integrarem a noção relativa a ela, deve poder ser expressa em proposições predicativas acerca dessa substância, o que envolve necessariamente conceitos.

\section{$* * *$}

Afastadas as duas soluções para o problema da prova sortuda examinadas por Hawthorne \& Cover, eu gostaria de apresentar, em largos traços, o que considero que seria a maneira mais adequada, no interior do sistema leibniziano, de sustentar a contingência de algumas - mas não de todas - as proposições acerca de indivíduos, evitando o problema da prova sortuda.

A minha posição envolve fundamentalmente conceder ao Princípio da Razão Suficiente um papel central na compreensão do que significa, para Leibniz, provar que um determinado predicado está contido na noção relativa a um certo indivíduo. De acordo com Leibniz, uma proposição como "César atravessou o Rubicão" é contingente pelo fato de não se poder demonstrar em um número finito de passos que o predicado referente à ação de travessia do Rubicão está contido na noção completa de César. Essa demonstração é impossível por ter toda ação realizada por um sujeito sua razão suficiente nas modificações do sujeito prévias à efetivação da ação. Somente se poderia demonstrar que a noção completa de César inclui a noção referente à ação de atravessar o Rubicão caso se recorresse ao conjunto de todas as modificações de César anteriores à 
travessia, dado que a travessia deriva desses estados. Quer dizer, somente poderíamos provar que a noção completa de César inclui a travessia do Rubicão se (a) dispuséssemos de uma noção de César que incluísse todas as suas infinitas modificações e se (b) pudéssemos abarcar de um só golpe com o nosso entendimento todas essas modificações. Obviamente não podemos satisfazer nenhuma dessas duas condições, o que torna impossível uma prova a priori de proposições que envolvam propriedades ou relações que surgem ou desaparecem em um determinado momento.

O ponto fundamental aqui é a ideia de que a demonstração da verdade de uma proposição que atribui uma propriedade ou relação transitória a um indivíduo não ocorre, em Leibniz, da maneira como parecem imaginar Adams ou Hawthorne \& Cover. Não se trata simplesmente de decompor uma noção relativa a uma substância individual - César, por exemplo - e constatar ou não a presença nela de um traço característico referente a uma determinada propriedade ou relação - a travessia do Rubicão, por exemplo -, como fazemos quando abrimos uma caixa e constatamos se ela contém ou não um determinado item que buscamos. O problema da prova sortuda surge e ganha seu sentido e relevância somente quando se considera que é de uma maneira análoga a essa que transcorreria a prova de uma proposição contingente. Seria exatamente em função da possibilidade de termos sorte ao retirarmos, por meio de uma análise, predicados de uma noção completa de uma substância individual e nos depararmos, então, em um dos passos ou lances iniciais, precisamente com o predicado cuja inerência ao sujeito queremos provar é que, Adams o suspeita, o fato de serem infinitos os predicados contidos em uma tal noção completa não seria suficiente para impedir que uma prova dessa natureza fosse realizada em passos finitos. Quando refletimos mais detidamente, contudo, acerca de como uma prova da inerência de um predicado na noção relativa a um indivíduo deve ocorrer, vemos que a própria base sobre a qual se assenta o problema da prova sortuda se desfaz. Senão vejamos.

Provar uma proposição predicativa consiste, de acordo com Leibniz, em demonstrar que seu predicado se deixa deduzir a partir de seu sujeito, isto é, que do conjunto dos outros elementos constitutivos da noção do sujeito se deixa inferir o predicado em questão. Isso significa que analisar a noção do sujeito e mostrar que ela inclui a noção de um determinado predicado envolve não propriamente a descoberta nela desse predicado 
ao, por assim dizer, percorrermos uma hipotética lista dos predicados que a compõem, mas sim, mais precisamente, a demonstração de que o conjunto dos predicados que já sabemos constituir essa noção é razão suficiente para a atribuição à substância individual da modificação expressa por esse predicado e, portanto, para a afirmação da inerência da noção do predicado na noção do sujeito ${ }^{13}$.

Mas, se for assim, então o problema da prova sortuda simplesmente não se coloca, pois, segundo Leibniz, nenhum conjunto finito de modificações de uma substância individual pode constituir uma razão suficiente para a ocorrência de uma modificação posterior. Pelo contrário, qualquer modificação de um indivíduo é determinada por todas as infinitas percepções e apetites anteriores a ela. Por uma questão de princípio, não pode haver, então, ainda que se tenha toda a sorte do mundo, uma prova a priori acerca da posse de uma propriedade temporal por parte de um sujeito, uma vez que, como vimos acima, provar a inerência do predicado no sujeito é demonstrar que o predicado se deixa derivar da noção da substância individual, o que, no caso dos predicados que expressam modificações temporais é absolutamente impossível, pois isso pressuporia uma consciência simultânea das infinitas percepções e apetites de um sujeito.

${ }^{1}$ Leibniz apresenta essa concepção em inúmeros textos. Para ilustrar, cito uma passagem de uma carta a Arnauld de julho de 1686: "toujours, dans toute proposition affirmative véritable, nécessaire ou contingente, universelle ou singulière, la notion du prédicat est comprise en quelque façon dans celle du sujet; praedicatum inest subjecto" (LEIBNIZ, 1993, p. 121).

${ }^{2}$ Cito apenas uma das inúmeras passagens em que Leibniz, apresenta essa distinção. Trata-se de um trecho do texto De Contingentia: “A distinção entre verdades necessárias e contingentes desvela o mistério, porém de uma maneira tal que apenas a compreenderão com facilidade aqueles que gozam de uma certa formação matemática. Certamente, nas proposições necessárias a análise levada até o fim chega a uma equação idêntica, a qual se supõe demonstrar a verdade com rigor geométrico. Por outro lado, nas proposições contingentes a análise torna-se infinita, procedendo de razão em razão de tal maneira que nunca se alcança uma demonstração completa” (LEIBNIZ, 2010, p. 214).

3 “... leur [das verdades de fato, das proposições contingentes] démonstration exigerait une analyse infinie, parce que le concept de toute chose concrète, de tout être individuel, enveloppe une infinité d'éléments ou des conditions (de rèquisits)" (COUTURAT, 1901, p. 211).

${ }^{4}$ O exemplo apresentado por Adams é o da negação de Pedro: "Even if infinitely many properties and events are contained in the complete concept of Peter, at least one of them will be

doispontos, Curitiba, São Carlos, vol. 11, n. 2, p.29-46, outubro, 2014 
proved in the first step of any analysis. Why couldn't it be Peter's denial? Why couldn't we begin to analyze Peter's concept by saying 'Peter is a denier of Jesus and...??” (ADAMS, 1994, p. 34).

5 "Cartesius enim ita argumentatur: Quiequid ex rei definitione demonstrari potest, illud de ea potest praedicari. Ex definitione autem DEI (quod sit Ens summe perfectum, seu ut Scholastici quidam efferebant, quo majus cogitari non potest) sequitur Existentia (nam existentia est perfectio, et id ipsum quod praetera existentiam involvit, utique foret majus seu perfectius); Ergo Existentia de Deo potest praedicari seu Deus existit. (...) Sed si rigorosa debet esse haec demonstratio, praedemonstranda est possibilitas.Scilicet non possumus de ulla Notione secure texere demonstrationes, nisi sciamus eam esse possibilem, nam de impossibilibus seu contradictionem involventibus etiam contradictoria possunt demonstrari, quae est ratio a priori cur ad definitionem realem requiratur possibilitas."

${ }^{6}$ O texto Que o Ente Perfeitíssimo Existe, de novembro de 1676, fornece um bom exemplo da formulação leibniziana do argumento ontológico.Ver LEIBNIZ, 1978, 7, p. 261-262.

${ }^{7}$ Hawthorne e Cover rejeitam essa solução por essa mesma razão: “there is a pressing difficulty confronting this escape from the problem of the lucky proof. The difficulty is that, when construed along the lines we have just explored, the infinite analysis doctrine renders too much contingent - too much even by Leibniz's own lights" (HAWTHORNE \& COVER, 2000, p. 155).

${ }^{8}$ Ninguém pode realizar a ação de atravessar o Rubicão - ou optar por não atravessá-lo - em um lugar outro que a região em que o rio se localiza. Atravessar o Rubicão não será também uma ação realizada pelo sujeito quando a travessia não for fruto de uma decisão tomada por este. Nesses sentido, bebês de colo, por exemplo, não atravessam o Rubicão, mas sim simplesmente são levados de um lado para o outro.

9 "in hac completa Petri possibilis notione quam Deo obversari concedo contineri non tantum essentialia, seu necessaria, quae scilicet ex notionibus incompletis sive specificis fluunt, adeoque ex terminis demonstrantur, ita ut contrarium implicet contradictionem, sed et contineri, existentialia ut ita dicam sive contingentia, quia de natura substantiae individualis est, ut notio ejus sit perfecta atque completa, omnesque circumstantias individuales etiam contingentes ad minima usque contineat".

10 "Videmur etiam hinc discere posse discrimen veritatum necessariarum ab aliis, ut scilicet verae necessariae sint quae ad identicas reduci possunt, aut quarum oppositae reduci possint ad contradictorias; et falsae impossibiles, quae ad contradictorias reduci possint, aut quarum oppositae reduci possint ad identicas" (LEIBNIZ, 2006, p. 758).

11 “Car tous les prédicats d'Adam dépendent d'autres prédicats du même Adam, ou n'en dépendent point. Mettant donc à part ceux qui dépendent d'autres, on n'a qu'a prendre ensemble tous les prédicats primitifs pour former la notion complète d'Adam suffisante à en deduire tout ce qui luit doit arriver autant qu'il faut pour en pouvoir rendre raison."

${ }^{12}$ Rodriguez-Pereira \& Lodge consideram que esses estados não podem ser conceitualizados sem que se faça referência aos estados de coisas aos quais eles inclinam, o que impediria que eles pudessem ser tomados como básicos (Cf. RODRIGUEZ-PEREIRA \& LODGE, 2011, p. 226). Minha tese é mais forte do que a deles, pois o que sustento é que uma conceitualização desses estados é, por princípio, impossível.

doispontos, Curitiba, São Carlos, vol. 11, n. 2, p.29-46, outubro, 2014 
${ }^{13}$ Ulysses Pinheiro defende uma concepção assemelhada.

\section{Referências bibliográficas}

ABRAHAN, W. 1969. "Complete Concepts and Leibniz's Distinction between Necessary and Contingent Propositions". In: Studia Leibnitiana, 1, pp. 263-279.

ADAMS, R. 1994. Leibniz. Determinist, Theist, Idealist. Oxford: Oxford University Press.

COUTURAT, L. 1901. La Logique de Leibniz. Paris: Felix Alcan.

COVER, J. and HAWTHORNE, J. 2000. "Infinite Analysis and the Problem of the Lucky Proof". In: Studia Leibnitiana, 32, pp. 151-165.

DICKER, G. 1982. "Leibniz on Necessary and Contingent Propositions”. In: Studia Leibnitiana, 14, pp. 221-232.

HAWTHORNE, J. \& COVER, J.A. 2000. "Infinite Analysis and Problem of the Lucky Proof”, Studia Leibnitiana, XXXII/2.

HUNTER, G. 1981. "Leibniz and the "Super-Essentialist" Misunderstanding”. In: Studia Leibnitiana, 13, pp. 123-132.

KNEBEL, S. 1996. "Leibniz, Middle Knowledge, and the Intricacies of World Design”, Studia Leibnitiana, 28, pp. 199-210.

LEIBNIZ, G.W. 1993. Discours de Métaphysique et Correspondance avec Arnauld. Introduction, texte et commentaire par LE ROY, G. Paris:Vrin. 1978. Die philosophischen Schriften, Band 7, herausgegeben von GERHARDT, C. I. , Hildesheim: George Olms Verlag.

2006. Sämtliche Schriften und Briefe, herausgegeben von der Preurischen bzw. der Deutschen Akademie der Wissenschaften zu Berlin, Reihe VI, Band 4., Berlim: Akademie Verlag. .2010. Obras Filosóficas y Científicas, Vol. 2: Metafísica, Granada:Editorial Comares. 
LODZINSKI, D. 1994. "Leibnizian Freedom and Superessentialism”, Studia Leibnitiana, 26, pp. 163-186.

MAHER, P. (1980). “Leibniz and Contingency”, Studia Leibnitiana, 12, pp. 236-242.

MARQUES, E. 2012. “Observações preliminares acerca da raiz da contingência em Leibniz”. In: Levy, L., Zingano, M., Pereira, L.C., Metafísica, Lógica e outras coisas mais. Rio de Janeiro: Nau Editora, pp. 33-51.

.2012. “A singularidade como raiz da contingência em Leibniz: considerações críticas acerca da solução de Couturat ao problema da contingência em Leibniz". In: Analytica, vol. 16, 1-2, pp. 119-131.

MEIJERING, T. 1978. “On Contingency in Leibniz's Philosophy”. In: Studia Leibnitiana, 10, pp. 22-59.

MONDADORI, F. 1973. "Reference, essentialism and modality in Leibniz's metaphysics”. In: Studia Leibnitiana, 5, pp. 73-101.

PINHEIRO, U. 2001. “Contingência e Análise Infinita em Leibniz”. In: Kriterion, 104, pp. 72-96.

RODRIGUEZ-PEREIRA, G. \& LODGE, P. 2011. "Infinite Analysis, Lucky Proof, and Guaranteed Proof in Leibniz". In: Archiv für Geschichte de Philosophie, 93, pp. 222-236.

RUSSELL, B. 1972. "Recent Work on the Philosophy of Leibniz", in Frankfurt, H. (ed.), Leibniz, a Collection of Critical Essays, Doubleday Anchor, pp. 365-400.

SHIGENAGA, T. 2014. "Rulling out Lucky Proofs", Archiv für Geschichte de Philosophie, 96, pp. 262-277.

VAILATI, E. 1986. "Leibniz on Necessary and Contingent Predication", Studia Leibnitiana, 18, pp. 195-210. 